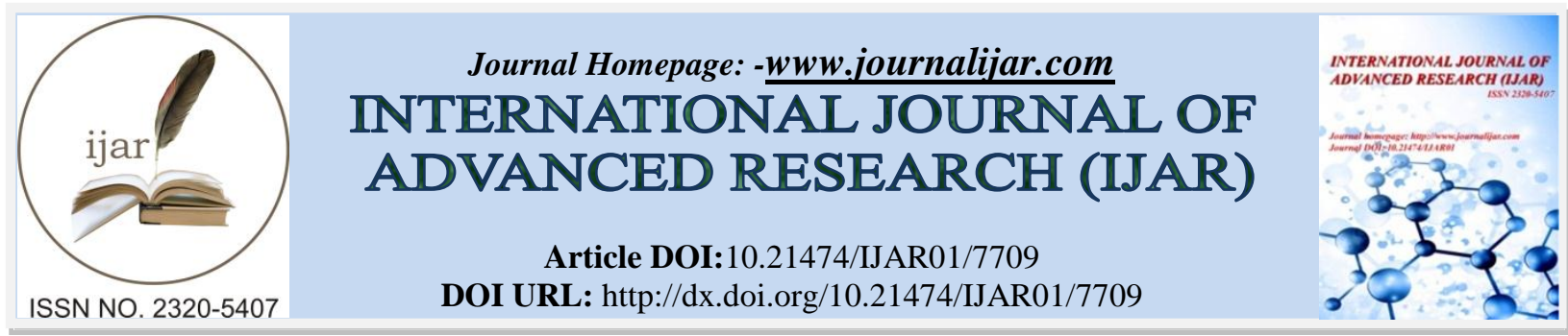

RESEARCH ARTICLE

\title{
IMMEDIATE IMPLANT PLACEMENT PLANNING IN MANDIBULAR POSTERIOR REGION USING CONE BEAM COMPUTED TOMOGRAPHY.
}

\author{
Dr. ManjariChaudhary, Dr. Ajay Bhoosreddy, Dr. Apurva Patil, Dr. AkankshaBhandari , Dr. Ashni \\ Chatterjee, Dr. Yash Aggarwal and Dr. Shuddhodhan Gaikwad.
}

\section{Manuscript Info}

Manuscript History

Received: 20 July 2018

Final Accepted: 26 August 2018

Published: September 2018

Keywords:-

Immediate Implant Placement, Inferior alveolar nerve canal, Cone Beam Computed Tomography.

\section{Abstract}

Background/aim: Dental Implant therapy has become an integral part of daily practice due to its high success rate but surgical mishaps, complications and damage of vital anatomical structures do occur. If proper diagnosis and treatment planning is done then implant surgeries can proceed uneventfully and can fulfil both the functional and aesthetic demands after osseointegration. The aim of this study was to determine the longest upright and tilted implants allowed to be placed in three posterior mandibular teeth areas in case of Immediate Implant Placement (IIP) with respect to a safe distance from the inferior alveolar canal (IAC) and the submandibular fossa, using cone beam computed tomography (CBCT).

Materials and Method: The 209 CBCT scanswere reviewed retrospectively of the subjects. The following were measured: distance from the tooth apex to the IAC, buccolingual width of the mandible which was determined at the axial section nearest to the middle of tooth's mesiodistal width, classification of mandibular cross-sectional morphology as per Sammartino et al (2008) and Chan H-L (2011), upright and tilted implant placement simulation, tilting anglethat allowed placement of the longest implant and availability of buccal and lingual cortical plate.

Results: As we progress posteriorly i.e., from second Premolar (PM) to Second Molar (M) the distance from tooth apex to IAC decreases significantly. The mean value between the teeth is increasing significantly. The mandibular cross-sectional ridge types are $\mathrm{U}$ (undercut), C (convergent); $\mathrm{P}$ (parallel) had a prevalence rate of $65 \%$, $23 \%$, and $14 \%$ respectively. The available width for both buccal and lingual cortical plate increased significantly from $2 \mathrm{PM}$ to $2 \mathrm{M}$. For the moreposterior regions the tilting angle was greater in orderto place the longest implant without causing any lingual perforation and damage to vital anatomic structures like the IAC.

Conclusions: Within the scope of this study, we have concluded that the distance from the tooth apex to IAC decreases in molar region as compared to premolar region. Whereas, buccolingual width of the mandible is greater in molars as compared to the premolars. Mandible has a tendency to be classified as "undercut" in more posterior regions. Therefore, there is a need for careful attention when the placement of 
an immediate implant is planned in this area. Alternative treatment option to avoid the violation of the lingual plate perforation includes the use of implant tilting. More posterior regions resulted in a restriction to place shorter implants in comparison to more anterior regions.

Copy Right, IJAR, 2018,. All rights reserved.

\section{Introduction:-}

Most of the implant surgeries can be carried out without any events and can fulfil both the functional as well as aesthetic demands with correct diagnosis and treatments planning but complications do occur such as damage to the vital anatomic structures. ${ }^{[1-3]}$

Immediate implant placement (IIP) into fresh extraction sockets has been documented to be a predictable treatment modality, with survival rates comparable to implants placed in healed ridges. However, there is a high risk in the posterior mandible region for successful IIP such as lingual plate perforation because of the location of the inferior alveolar canal (IAC) and the concavity of the submandibular fossa. ${ }^{[4-6]}$

Dental implant surgery demonstrates a 6.5\%-37\% incidence of temporary or permanent paralysis, or even sensory loss, because of inferior alveolar nerve damage in the IAC resulting from the poor implant planning. ${ }^{[7-10]}$ The assessment of the location of the mandibular canal, the maxillary sinuses, and the nasal cavity, as well as the angulation of the alveolar crest and, in particular, the bone volume, is often a prerequisite for an appropriate planning. There are radiographic techniques available to guide the clinicians in implant treatmentplanning. Panoramic radiography and intraoral radiography give only information in two dimensions. Hence, tomographic techniques are essential. ${ }^{[11]}$

Among the disadvantages of the Computed Tomography (CT) technique is its high cost, and delivers considerably high radiation dose. ${ }^{[12]}$ Whereas, a lower radiation dose has been reported with the CBCT compared with conventional CT. ${ }^{[13]}$

Thus, the aim of the study is to determine the longest upright and longest tilted implants allowed to be placed in three mandibular teeth areas (second premolar [2PM], first molar [1M], and second molar [2M]) in case of IIP, using cone beam computed tomography (CBCT).

\section{Method AndMaterials:-}

Objectives

1. To determine the distance from the tooth apex to the IAC.

2. To determine buccolingual width of the mandible.

3. To measure the available width of buccal and lingual cortical plates.

4. To analyseupright and tilted implant placement simulation and measurement of tilting angle.

\section{Subjects}

This present study had retrospectively reviewed 107 mandibular CBCT scans of patients from the Department of Oral Medicine and Radiology selected from the database. CBCT scanning was performed with a Sirona CBCT system. Measurementswere obtained on the transversal sections ofthe selected teeth, with the use of computer software Galileo.

\section{Inclusion and Exclusion Criteria}

The following inclusion criteria were:

1. Presence of mandibular 2PM, 1M, and 2M with completely formed apices.

2. Presence of opposing maxillary teeth to provide information for implant angulations. 
The following exclusion criteria were:

1. The presence of any technicalartefactswhich hindered the evaluation of the concerned structures.

2. Those CBCT scans which already had a missing tooth, an implant, or grafted alveolar ridge were excluded from this study.

\section{Measurements}

The Distance from the Tooth Apex to the IAC

The mandibular 2PM, 1M, and 2M were evaluated on CBCT and a vertical line was drawn from the apical level of the $2 \mathrm{PM}$ or the apical level of the mesial root of the $1 \mathrm{M}$ and $2 \mathrm{M}$ to the superior border of the IAC (Fig 1). The available bone apical to the socket was defined as adequate for IIP when the distance from the tooth apex to IAC was $\geq 6 \mathrm{~mm}$. When the distance measured was $<6 \mathrm{~mm}$, IIP was considered high risk for injury of the inferior alveolar nerve (IAN).

\section{Buccolingual Width of the Mandible}

The buccolingual width of the mandible $2 \mathrm{~mm}$ below the buccalcrestal level was measured (Fig 2). It was measured from inner buccal cortical plate to inner lingual cortical plate. The width was determined at the axial section nearest to the middle of the tooth's mesiodistal width.

\section{Classification of Mandibular Cross-Sectional Morphology}

Three types of mandibular morphology were determined according to previously described guidelines in order to identify the mandibular ridge shape. ${ }^{[14]}$

They are:

1. Convergent $(\mathrm{C})$ type: The base of the ridge was wider than its crestal part

2. Parallel (P) type: A more or less parallel ridge form

3. Undercut $(\mathrm{U})$ type: A ridge with a narrow base to a wider crest with a prominent point on the lingual plate, thus causing a lingual undercut (Fig 3).

\section{Measurement of the Available Width of Buccal and Lingual Cortical Plate}

To assess the amount of available width of buccal and lingual cortical plates separately, $2 \mathrm{~mm}$ below the buccal crestal level was measured. The available width for buccal cortical plate was measured from outer buccal cortical plate to inner buccal cortical plate (Fig 4a) and the available width for lingual cortical plate was measured from outer lingual cortical plate to inner lingual cortical plate (Fig 4b)

\section{Upright and Tilted Implant Placement Simulation and Measurement Of Tilting Angle}

To determine if the implant would present high risk for lingual plate perforation during immediate implant placement, a simulated parallel root form implant was positioned $2 \mathrm{~mm}$ below the buccalcrestal level, vertically in an ideal implant position according to the position of the real tooth crown (Fig 5a). The proper angulations to the implant were also provided in the panoramic view (Fig 5b). The long axis of the opposing maxillary tooth determined the buccolingual angulations of the implant. Therefore, long axis of the implant placed was in line with that of the opposing maxillary tooth. The longest implant which can be placed without lingual plate perforation, keeping the minimum $2.0 \mathrm{~mm}$ safe distance from the IAC and from the external cortical bone was determined for each tooth considered for this study i.e., 2PM, 1M, 2M (Fig 5c).

\section{Statistical Analyses}

The variations were evaluated according to the tooth (2PM, 1M, 2M). Mean value was calculated for each tooth and the comparison between the teeth was done using ANOVA test. Statistical significance was considered as $P<0.05$.

\section{Results:-}

This present study had retrospectively reviewed 107 CBCT mandibular scans fulfilling the inclusion as well as exclusion criteria consisting of 59 males (M) and 48 females (F) with a mean age of 49.1 years.

\section{The Distance from the Tooth Apex to the IAC}

As we progress posteriorly i.e., from $2 \mathrm{PM}$ to $2 \mathrm{M}$, the distance from tooth apex to IAC decreases significantly. The available bone apical to the socket was defined as adequate for IIP when the distance from the tooth apex to IAC 
was $\geq 6 \mathrm{~mm}$, but the mean value of the distance from the tooth apex to IAC for $2 \mathrm{PM}, 1 \mathrm{M}, 2 \mathrm{M}$ were $5.91 \mathrm{~mm}$, $5.11 \mathrm{~mm}, 3.69 \mathrm{~mm}$ respectively. Thus, the mean values were less than $6 \mathrm{~mm}$ safe distance. (TABLE 1 and GRAPH 1)

\section{Buccolingual Width of the Mandible}

As we progress from $2 \mathrm{PM}$ to $2 \mathrm{M}$, the mean value between the teeth is increasing significantly. The mean value of the buccolingual width of the mandible for $2 \mathrm{PM}$ is $4.79 \mathrm{~mm}, 1 \mathrm{M}$ is $6.29 \mathrm{~mm}$ and $2 \mathrm{M}$ is $7.33 \mathrm{~mm}$. This shows that buccolingual width of the mandible is greatest for 2M and shortest for 2PM (TABLE 1 and GRAPH 2)

\section{Classification of Mandibular Cross-Sectional Morphology}

The mandibular cross-sectional ridge types are $\mathrm{U}$ (undercut), $\mathrm{C}$ (convergent), $\mathrm{P}$ (parallel) had a prevalence rate of $65 \%, 23 \%$, and $14 \%$ respectively. Thus, the mandibular cross-sectional morphology is considered to be undercut type in most of the cases. (PIE CHART)

\section{Available Width of Buccal and Lingual Cortical Plate}

The mean value for available width for both buccal and lingual cortical plate increased significantly from 2 PM to $2 \mathrm{M}$. The mean value for available width of buccal cortical plate for 2PM, $1 \mathrm{M}$ and $2 \mathrm{M}$ are $1.56 \mathrm{~mm}, 1.72 \mathrm{~mm}$ and $1.74 \mathrm{~mm}$ respectively whereas, for available width of lingual cortical plate, the mean values for $2 \mathrm{PM}, 1 \mathrm{M}$ and $2 \mathrm{M}$ are $1.77 \mathrm{~mm}, 1.89 \mathrm{~mm}$ and $1.98 \mathrm{~mm}$ respectively. Hence, we can conclude that the available width of buccal as well as lingual cortical plate is highest for $2 \mathrm{M}$ and lowest for 2PM (TABLE 2, GRAPH 3 and 4)

\section{Implant Placement Simulation and Measurement of Tilting Angle}

The implant would present high risk for lingual plate perforation during immediate implant placement due to the anatomy of the mandible. More posteriorregions (i.e. mandibular $2 \mathrm{M}$ ) resulted in the possibility of placing shorterimplants in comparison to more anterior regions (i.e. mandibular 2PM).Moreover, for the moreposterior regions the tilting angle was greater in orderto place the longest implant without causing any lingual perforation and damage to vital anatomic structures like the IAC. (TABLE 3 and GRAPH 5)

\section{Discussion:-}

During the implant placement, care should be taken to protect the vital anatomic structures like the inferior nerve canal (IAC). Improper positioning of the implant may lead to damage to the IAC. Hence, the minimum safe distance from the IAC considered is $2.0 \mathrm{~mm} .{ }^{[14]}$ Four millimeters of bone height apical to the extraction socket is assumed to be necessary for immediate implant anchorage. ${ }^{[15]}$ Thus, the available bone apical to the socket was defined as adequate for IIP when the distance from the tooth apex to IAC was $\geq 6 \mathrm{~mm}$, but, the mean values in this study are less than $6 \mathrm{~mm}$ safe distance. Chrcanovic $\mathrm{BR}^{[16]}$ found out that the mean values were less than the critical $6 \mathrm{~mm}$ safe distance.

The buccolingual width of the mandible $2 \mathrm{~mm}$ below the buccalcrestal level, there was an increase in the mean value toward more posterior sites (from $2 \mathrm{PM}$ to $2 \mathrm{M}$ ). The similar results were found in the study done by Braut $\mathrm{V}^{[17]}$ in dentulous individuals.

A study done by Lin $\mathrm{MH}$ et al ${ }^{[18]}$ observed that the most prevalent cross sectional ridge type in the posterior mandible region was the $U$ type ridge i.e. the Undercut type. The results were similar to this study wherein the $U$ type ridge was most prevalent $(65 \%)$. The cross sectional morphology of the mandible had a tendency to be classified as "undercut" in more posterior regions. The mandibular cross-sectional morphologic differences have a deep impact during IIP since they can be major potential risk of causing lingual plate perforation.

The tilting of an implant may pose restorative problems since it follows the long axis of occlusal forces in the posterior regions. ${ }^{[19]}$ However, the results of a recent meta-analysis published by Chrcanovic BR ${ }^{[20]}$ suggested that the differences in angulation of dental implants might not affect the implant survival or the marginal bone loss. Also, the use of individualized abutments with an angled screw channel may minimize the prosthetic issues. ${ }^{\text {[21] }}$ 


\section{Conclusion:-}

Within the scope of this study, we have concluded that the distance from the tooth apex to IAC decreases in molar region as compared to premolar region. Whereas, buccolingual width of the mandible is greater in molars as compared to the premolars. The available width of both buccal as well as the lingual cortical plate is greater for more posterior regions. Mandible has a tendency to be classified as "undercut" in more posterior regions. Therefore, there is need for careful attention when the placement of an immediate implant is planned in this area. Alternative treatment options to avoid the violation of the lingual plate perforation include the use of tilting of the implant. More posterior regions resulted in a restriction to place shorter implants in comparison to more anterior regions.

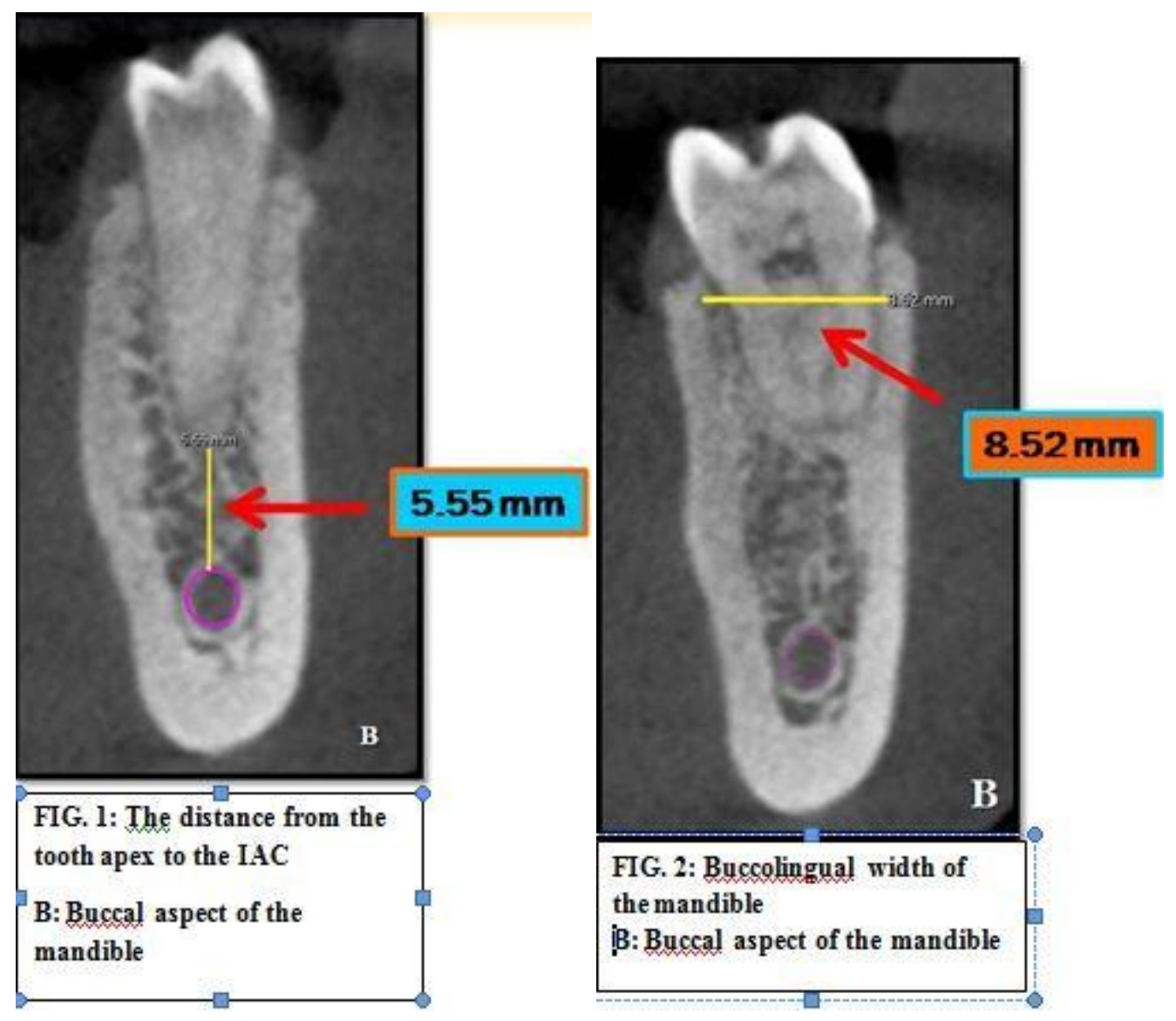




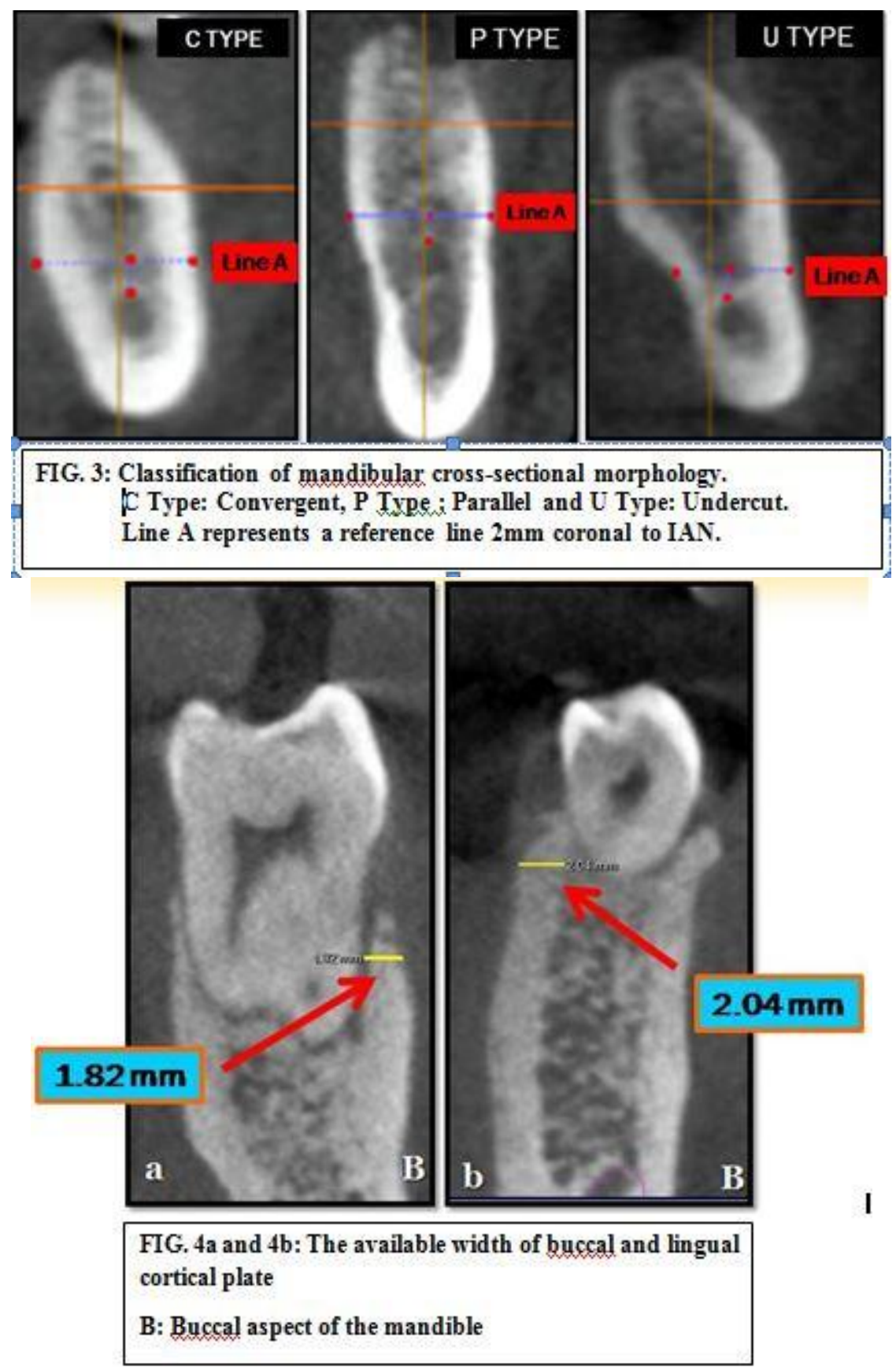



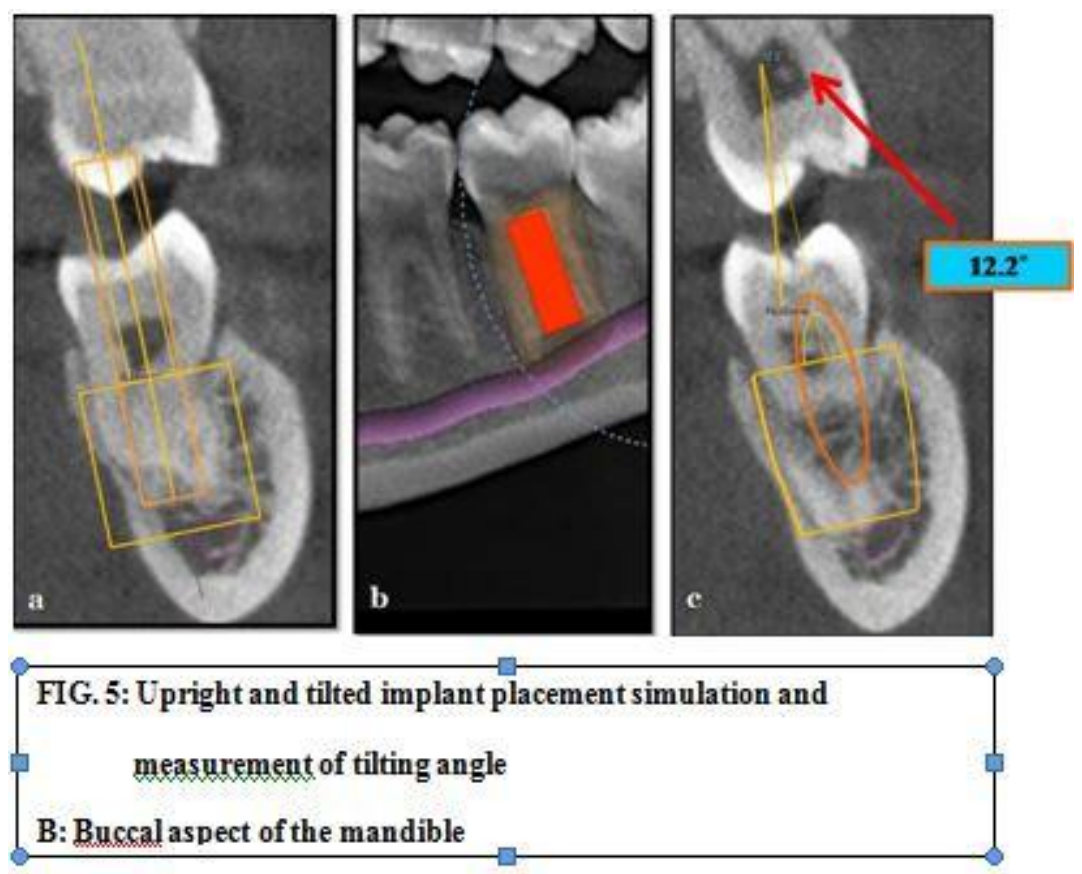

Table 1:-The distance from the tooth apex to the inferior alveolar canal and thebuccolingual width of the mandible

\begin{tabular}{|c|c|c|c|}
\hline \multicolumn{2}{|c|}{ Distance from the tooth apex to IAC $(\mathrm{mm})$} & \multicolumn{2}{c|}{ Buccolingual width of the mandible(mm) } \\
\hline TOOTH & MEAN & TOOTH & MEAN \\
\hline $2^{\mathrm{ND}}$ PREMOLAR & 5.91 & $2^{\mathrm{ND}}$ PREMOLAR & 4.79 \\
\hline $1^{\mathrm{ST}}$ MOLAR & 5.11 & $1^{\mathrm{ST}}$ MOLAR & 6.29 \\
\hline $2^{\mathrm{ND}}$ MOLAR & 3.69 & $2^{\mathrm{ND}}$ MOLAR & 7.33 \\
\hline
\end{tabular}

Table 2:-Available width of buccal and lingual cortical plate

\begin{tabular}{|c|c|c|c|}
\hline \multicolumn{2}{|c|}{ Distance from the tooth apex to IAC(mm) } & \multicolumn{2}{c|}{ Buccolingual width of the mandible(mm) } \\
\hline TOOTH & MEAN & TOOTH & MEAN \\
\hline $2^{\mathrm{ND}}$ PREMOLAR & 5.91 & $2^{\mathrm{ND}}$ PREMOLAR & 4.79 \\
\hline $1^{\mathrm{ST}}$ MOLAR & 5.11 & $1^{\mathrm{ST}}$ MOLAR & 6.29 \\
\hline $2^{\mathrm{ND}}$ MOLAR & 3.69 & $2^{\mathrm{ND}}$ MOLAR & 7.33 \\
\hline
\end{tabular}

Table 3:-Tilting angle for the implant

\begin{tabular}{|c|c|}
\hline \multicolumn{2}{|c|}{ Tilting angle for the implant required (degree) } \\
\hline TOOTH & MEAN \\
\hline $2^{\mathrm{ND}}$ PREMOLAR & 3.04 \\
\hline $1^{\mathrm{ST}}$ MOLAR & 8.74 \\
\hline $2^{\mathrm{ND}}$ MOLAR & 12.41 \\
\hline
\end{tabular}



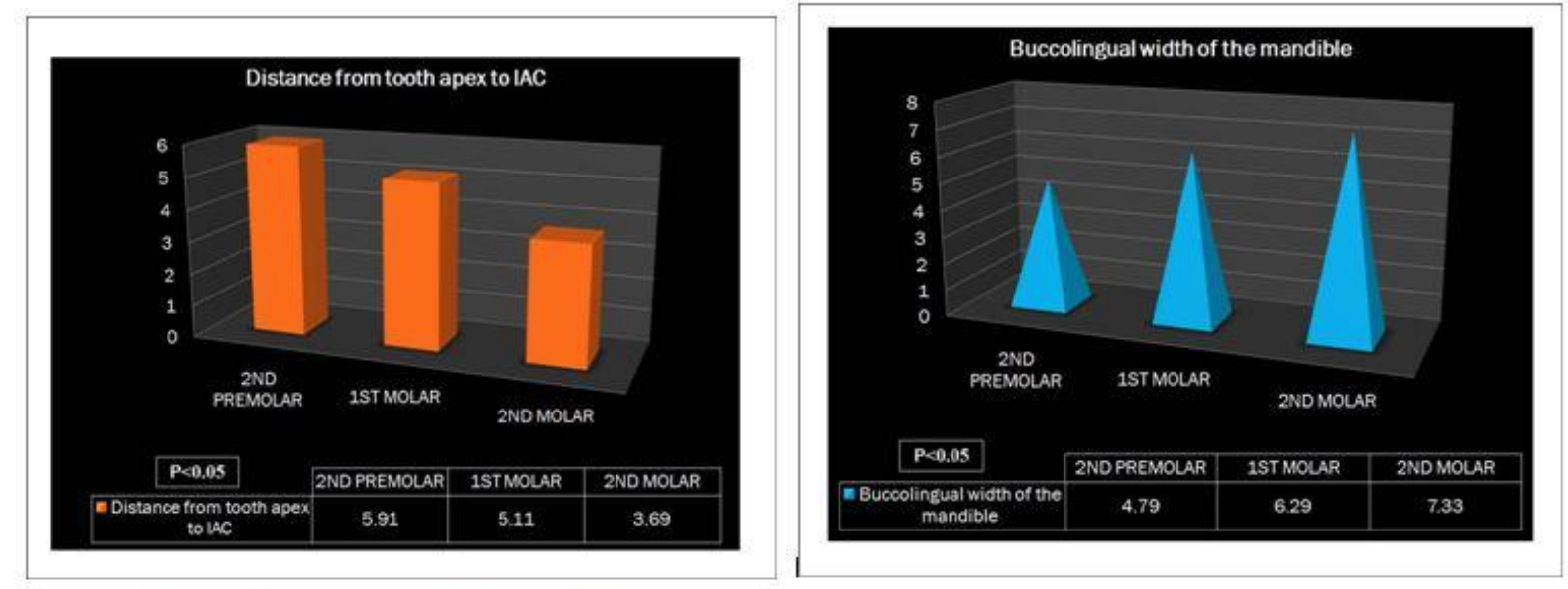

GRAPH 1: Distance from the tooth apex to IAC

GRAPH 2: Buccolingual width of the mandible

\begin{tabular}{|c|c|c|c|}
\hline \multicolumn{2}{|c|}{ Availability of buccal cortical plate $(\mathrm{mm})$} & \multicolumn{2}{c|}{ Availability of lingual cortical plate $(\mathrm{mm})$} \\
\hline TOOTH & MEAN & TOOTH & MEAN \\
\hline $2^{\mathrm{ND}}$ PREMOLAR & 1.56 & $2^{\mathrm{ND}}$ PREMOLAR & 1.77 \\
\hline $1^{\mathrm{ST}}$ MOLAR & 1.72 & $1^{\mathrm{ST}}$ MOLAR & 1.89 \\
\hline $2^{\mathrm{ND}}$ MOLAR & 1.74 & $2^{\mathrm{ND}}$ MOLAR & 1.98 \\
\hline
\end{tabular}
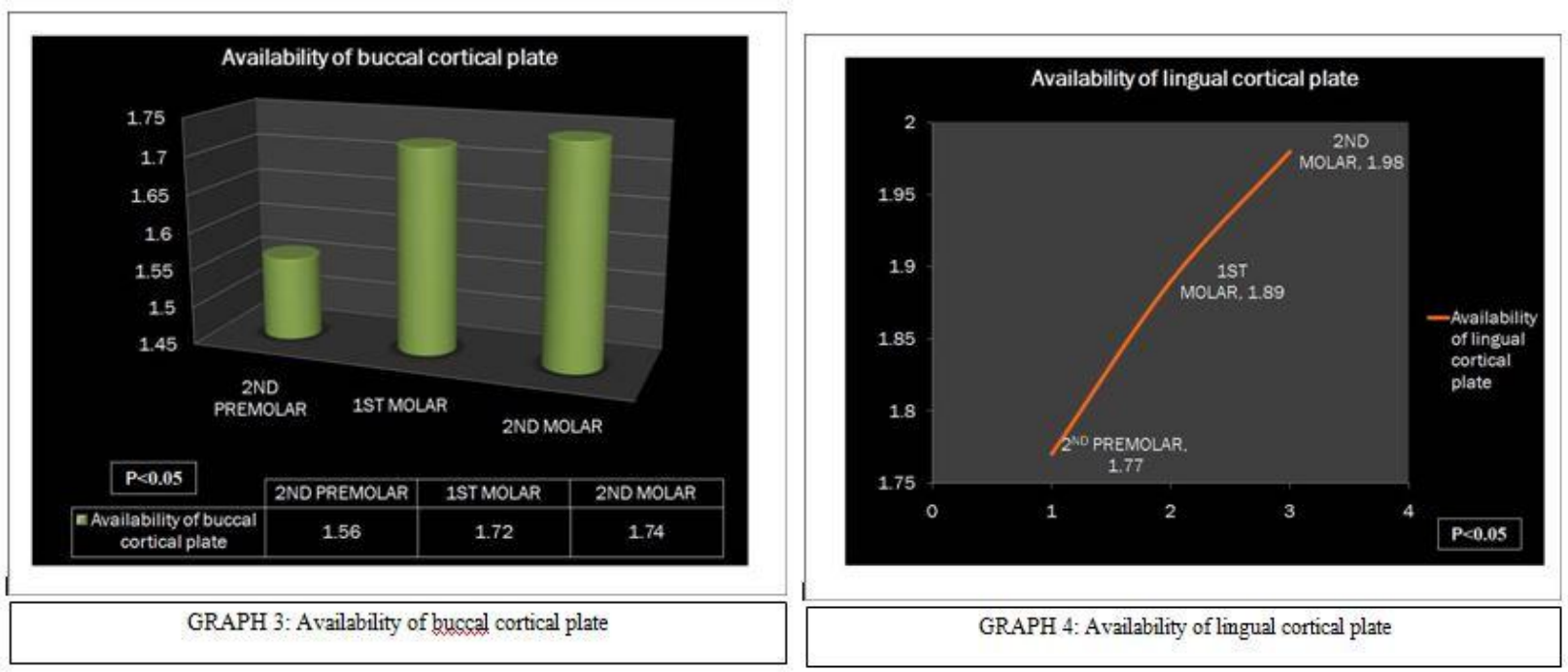


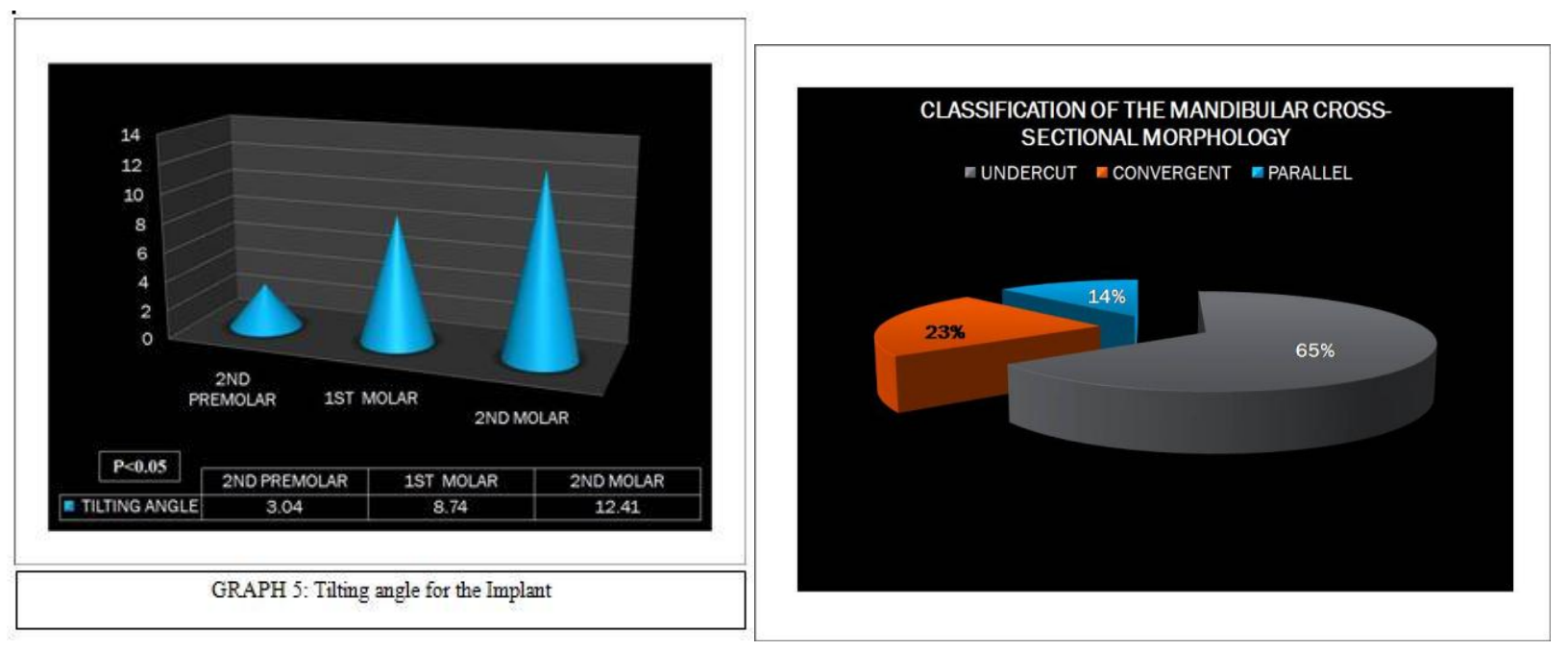

\section{References:-}

1. Greenstein G, Cavallaro J, Romanos G, Tarnow D. Clinical recommendations for avoiding and managing surgical complications associated with implant dentistry: a review. J Periodontol 2008; 79: 1317-1329.

2. Chrcanovic BR, Custodio AL. Mandibular fractures associated with endosteal implants. Oral MaxillofacSurg 2009;13: 231-238.

3. Chan HL, Brooks SL, Fu JH, Yeh CY, Rudek I, Wang HL. Cross-sectional analysis of the mandibular lingual concavity using cone beam computed tomography. Clin Oral Implants Res 2011;22: 201-206

4. Chrcanovic BR, Martins MD, Wennerberg A. Immediate placement of implantsinto infected sites: a systematic review. Clin Implant Dent Relat Res2015;17 (Suppl 1):e1-e16.

5. Chrcanovic BR, Albrektsson T, Wennerberg A. Dental implants inserted in fresh extraction sockets versus healed sites: a systematic review and meta-analysis. J Dent 2015;43: 16-41.

6. Greenstein G, Cavallaro J, Tarnow D. Practical application of anatomy for the dental implant surgeon. J Periodontol 2008;79: 1833-1846.

7. R. Bartling, K. Freeman, and R. A. Kraut, "The incidence of altered sensation of the mental nerve after mandibular implant placement," Journal of Oral and Maxillofacial Surgery 1999; 57(12): 1408-1410.

8. R. Kubilius, G. Sabalys, G. Juodzbalys, and V. Gedrimas, "Traumatic damage to the inferior alveolar nerve sustained in course of dental implantation. Possibility of prevention," Stomatologija 2004; 6(4):106-110

9. D. Wismeijer, M. A. J. Van Waas, J. I. J. F. Vermeeren, and W. Kalk. Patients' perception of sensory disturbances of the mental nerve before and after implant surgery: a prospective study of 110 patients. The British Journal of Oral and Maxillofacial Surgery 1997; 35(4) 254-259.

10. D. van Steenberghe, U. Lekholm, C. Bolender et al. Applicability of osseointegrated oral implants in the rehabilitation of partial edentulism: a prospective multicenter study on 558 fixtures. The International Journal of Oral and MaxillofacialImplants 1990; 5(3) 272-281.

11. Lofthag-Hansen S., Gröndahl K., OdontDr, Ekestubbe A. Cone-Beam CT for Preoperative Implant Planning in the Posterior Mandible: Visibility of Anatomic Landmarks. Clinical Implant Dentistry and Related Research 2009;11(3):246-255.

12. Ekestubbe A., Gröndahl K., Ekholm S., Johansson P.E., Gröndahl H-G. Low-dose tomographic techniques for dental implant planning. Int J Oral Maxillofac Implants 1996; 11:650-659.

13. Ludlow J.B., Davies-Ludlow L.E., Brooks S.L., Howerton W.B. Dosimetry of 3 CBCT devices for oral and maxillofacial radiology: CB Mercuray, NewTom 3G and i CAT. DentomaxillofacRadiol 2006; 35:219-226.

14. Sammartino, G., Marenzi, G., Citarella, R., Ciccarelli, R. \&Wang, H.L. Analysis of the occlusal stress transmitted to the inferior alveolar nerve by an osseointegrated threaded fixture. Journal of Periodontology 2008; 79: $1735-1744$.

15. Froum S. J. Immediate placement of implants into extraction sockets: rationale, outcomes, technique. Alpha Omegan 2005; 98: 20-35.

16. Chrcanovic BR, Machado V, Gjelvold B, Immediate implant placement in the posterior mandible: A cone beam computed tomography study. Quintessence international 2016;47(6): 505-514 
17. Braut V, Bornstein MM, Lauber R, Buser D. Bone dimensions in the posterior mandible: a retrospective radiographic study using cone beam computed tomography. Part 1: analysis of dentate sites. Int J Periodontics Restorative Dent 2012; 32: 175-184.

18. Lin MH, Mau LP, Cochran DL, Shieh YS, Huang PH, Huang RY. Risk assessment of inferior alveolar nerve injury for immediate implant placement in the posterior mandible: a virtual implant placement study. J Dent 2014; 42: 263-270.

19. Misch C. E, Bidez M.W. Implant-protected occlusion: a biomechanical rationale Compendium 1994; 15:1330, $1332,1334$.

20. [20] Chrcanovic BR, Albrektsson T, Wennerberg A. Tilted versus axially placed dental implants: A metaanalysis. J Dent 2015; 43: 149-170.

21. [21] Gjelvold B, Sohrabi M, Chrcanovic BR. Angled screw channel: an alternative to cemented single-implant restorations. A report of three cases. Int J Prosthodont 2016; 29: 74-76. 